\title{
Some Variable Facts of Liver: Embryological and Clinical Perspective
}

\author{
ALOK SAXENA, KISHOR KUMAR AGARWAL, CHARUL JAKHWAL, SHIVALI SINGH, AMAL RANI DAS
}

\begin{abstract}
Introduction: Liver is largest gland in the body and shows rare variation. Additional fissure, additional lobes, enlarged papillary process, variations of gall bladder are more common. Morphological variations have been classified into congenital or acquired.
\end{abstract}

Aim: To evaluate embryological rational of rare variations of liver and find out their impact on diagnostic and clinical procedures.

Materials and Methods: We studied 20 formalin fixed liver specimens in Anatomy Department during undergraduate teaching to find out variant gross morphological features of liver.

Results: Some rare variations were observed like grooves on hepatic surface (10\%), tunnel for ligamentum teres (15\%), enlarged papillary process $(10 \%)$, absence of quadrate lobe (5\%), additional fissures (20\%), lingular process (15\%).

Conclusion: Atrophy, agenesis, presence of accessory lobes, additional fissures may mislead the diagnostic procedures. Therefore, the knowledge of these variations may be a fruitful finding for diagnosticians as well as surgeons.

Keywords: Caudate lobe, Gall bladder, Ligamentum teres, Papillary process, Quadrate lobe

\section{INTRODUCTION}

Liver, a wedge shape organ is present in the right hypochondrium and epigastrium and extends in to left hypochondrium up to left lateral line. Attachment of falciform ligament, fissure for ligamentum venosum and ligamentum teres divide it in to right and left lobes. Quadrate lobe is the part of right lobe although functionally related with left lobe [1]. Caudate lobe occupying posterior surface of liver is comprised of two parts: Spiegel's lobe or Couinaud's segment and paracaval portion. A caudate lobe may project a papillary process from its left [2]. Lobar anatomy and site of hepatic lesions can be well understood with the help of major fissures [3]. Ligamentum teres hepatis, an embryological remnant of left umbilical vein lodges in the fissure for ligamentum teres on inferior surface of liver [3]. Hepatic anomalies may be due to excessive growth during embryonic life or due to faulty development [4]. Congenital anomalies are rare in liver but still few have been documented viz. agenesis of hepatic lobes, absence of segment, deformed lobes, lobar atrophy, transposition of gall bladder and Riedel's lobe [5]. Aim of the study was to evaluate the anomalous findings in liver, their source of origin and their impact on diagnostic and clinical procedures.

\section{MATERIALS AND METHODS}

A retrospective cohort study was done on twenty formalin fixed adult livers in the Department of Anatomy, Government Medical College, Srinagar, Uttarakhand. This study was conducted for a period of three months since August October 2015. Only healthy adult livers were included for the study. Rotten, degenerated, under developed livers were excluded from the study. Samples were collected by using simple random sampling method. For this purpose each liver was observed to facilitate visualization of diaphragmatic and visceral surfaces. Findings of accessory fissures and any other significant abnormality was also noticed. Dimensions of caudate lobe was measured in each liver using calliper to ascertain its shapes. The distinct morphological features were recorded on a separate data sheet. Photographic documentation of anatomical variations was done.

\section{RESULTS}

It is noteworthy that five livers (25\%) present in collection were considered to be anatomically normal in appearance whereas, 15 livers (75\%) showed a range of variations. 


\section{Variations of Hepatic Lobes}

Four livers were encountered with multiple grooves on anterior surface of right lobe. The length of caudate lobe exhibited a range from 5 to $8.1 \mathrm{~cm}$ and width from 3.5 to $4.2 \mathrm{~cm}$. Caudate lobes with rectangular, square and pear shapes were identified. Enlarged papillary processes were present only in two livers. We came across only one liver with absent quadrate lobe. A lingular process from left lobe was also a significant finding in three specimens [Table/Fig-1,2].

\section{Variant Ligamentum Teres}

Four livers were observed with absent fissure for ligamentum teres. Out of them three specimens showed tunnel for ligamentum teres [Table/Fig-3] and one liver showed incomplete ligamentum teres not extending to inferior border of liver.

\section{Presence of Additional Fissures}

Four livers showed additional fissure on hepatic surface.

I. An incomplete vertical fissure running downward from upper border of quadrate lobe

II. An oblique fissure extending from right margin of porta hepatis to inferior border of right lobe of liver

III. An oblique fissure extending from right margin of fossa for gall bladder to inferior border of right lobe of liver [Table/ Fig-4]
IV. A transverse fissure dividing the quadrate lobe into upper and lower parts [Table/Fig-5].

V. Variations of gall bladder.

Among 20 livers 11 showed anomalous gall bladder. In nine livers the gall bladders were short and their fundus did not project beyond the inferior border of liver. Two bladders were enlarged out of which one was devoid of fossa for gall bladder [Table/Fig-2].

\section{Multiple Variations in Single Liver}

Among 20 liver studied two specimens revealed more than two variations:

\section{Case 1}

An enlarged papillary process extending medially from the caudate lobe of liver was observed. Caudate lobe was considerably bigger in size (length $7 \mathrm{~cm}$, width $4 \mathrm{~cm}$ ) overlapping the inferior vena cava. We also observed interconnected left lobe with quadrate lobe due to presence of tunnel for ligamentum teres. A flask shaped gall bladder in the fossa for gall bladder was also observed [Table/Fig-3].

\section{Case 2}

An enlarged papillary process with length and width of 5.5 $\mathrm{cm}$ and $3 \mathrm{~cm}$ respectively was noticed [Table/Fig-5]. We observed a horizontal fissure dividing the quadrate lobe into upper and lower parts. Multiple grooves were present on the
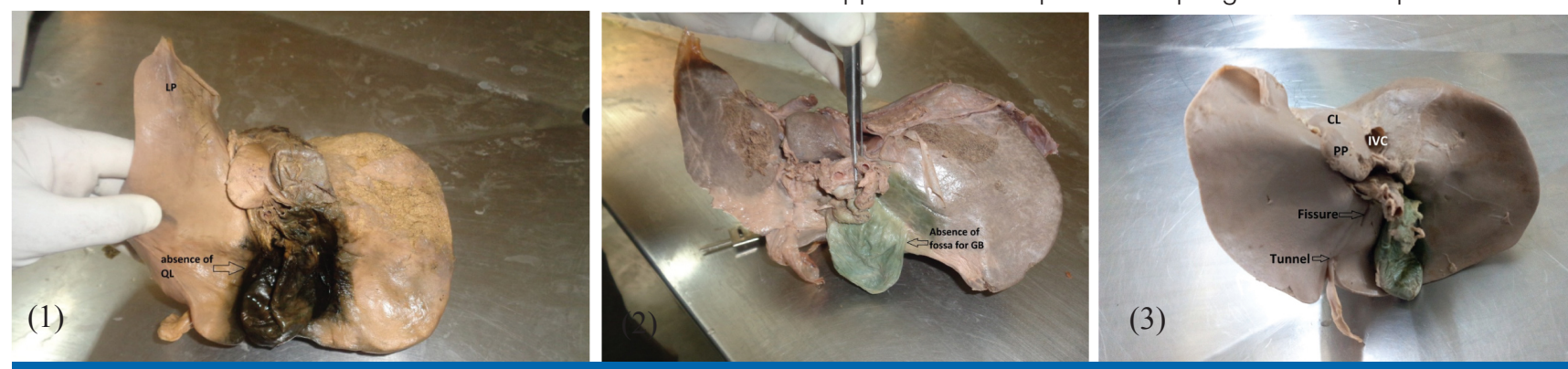

[Table/Fig-1]: Picture showing absence of quadrate lobe (QL) along with lingular process (LP), an extension of left hepatic lobe.

[Table/Fig-2]: Liver with absence of fossa for gall bladder. A lingular process can also be observed. [Table/Fig-3]: Picture appreciating enlarged caudate lobe (CL), prominent papillary process (PP), an additional vertical fissure and tunnel for ligamentum teres.
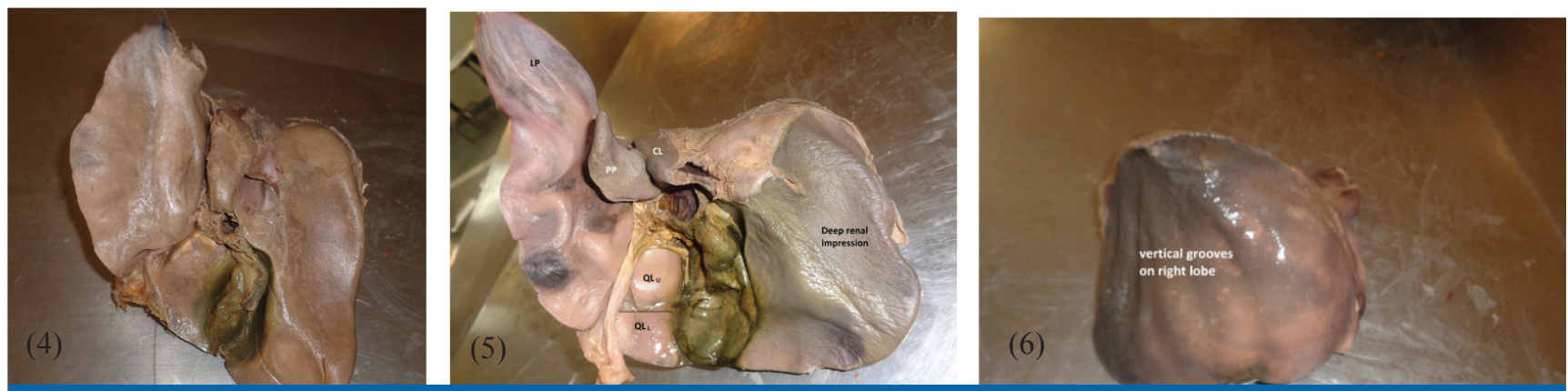

[Table/Fig-4]: An oblique fissure from right margin of fossa for gall bladder to right inferior margin. [Table/Fig-5]: Liver with lingular process (LP) and prominent papillary process (PP). An arrow representing a transverse fissure dividing quadrate lobe into upper (QLU) and lower lobe (QLL). [Table/Fig-6]: Liver showing vertical grooves due to thoracic wall impression related to anterolateral surface. 
anterior surface of right hepatic lobe [Table/Fig-6]. A lingular process from left lobe was also a significant finding. A deep renal impression was also observed in this specimen [Table/ Fig- 5].

\section{DISCUSSION}

Growth of liver occurs during $3^{\text {rd }}$ week of intrauterine life. Inspite of its complex development, gross anomalies are uncommon but variations may be congenital or acquired [6]. We examined 20 formalin fixed livers to find out such rare variations, and observed a range of variations when compared with previous studies [Table/Fig-7]. These variations were also categorized according to Netter's classification [7] [Table/ Fig-8]. Hepatic papillary process is an extension from medial aspect of caudate lobe. It is present between the fossa for gall bladder and fossa for inferior vena cava. Twenty one prominent papillary processes were identified in a study conducted on 100 caudate lobes [2]. A CECT finding showed a tongue like projection i.e prominent papillary process of $4.6 \times 1.2 \mathrm{~cm}$ [8]. A prominent process may mimic a mass lesion in sonographic appearance. Since, the echogenicity of this process is similar to hepatic parenchyma, it may lead to error during diagnostic procedures [9]. Although CT is the modality of choice for hepatic morphology still the papillary process may be confused with extrahepatic lesion since it may appear as separate entity in CT images. Its lucent appearance on CT may misdiagnosed it as enlarged porta hepatis node [10].

A study conducted on 55 liver specimens revealed one specimen with absence of fissure for ligamentum teres [3]. Patil et al., found only two cases with same variation in his study of 50 livers [11]. A case reported by Nayak et al., revealed tunnel for ligamentum teres [12]. We have come across four livers where fissure for ligamentum teres was absent. Out of them three specimens showed tunnel for ligamentum teres and one liver with incomplete ligamentum teres not extending to inferior border of liver. Inadequate separation of liver into right and left lobe might be a cause for tunnel. Presence of some air can be visualised in fissure in case of pneumoperitoneum. Radiographic images shows a vertically directed area of hyper lucency [13]. Presence of tunnel in place of fissure might shadow this hyperlucent area which may lead to wrong diagnosis [12]. It is worth noticing that absence of fissure for ligamentum teres may alter the normal anatomy of quadrate lobe. A fusion of quadrate lobe and left lobe was reported in $20 \%$ cases in present study. We scrutinized four livers with additional fissure on quadrate lobe and inferior surface of right lobe. Any collection

\begin{tabular}{|l|c|c|c|c|c|c|c|}
\hline \multirow{2}{*}{ Authors } & \multirow{2}{*}{$\begin{array}{c}\text { No. of } \\
\text { cases }\end{array}$} & \multicolumn{6}{|c|}{ Frequency of types of variations (\%) } \\
\cline { 5 - 8 } & & $\begin{array}{c}\text { Groove on } \\
\text { anterior surface }\end{array}$ & $\begin{array}{c}\text { Absence } \\
\text { of Q.L }\end{array}$ & $\begin{array}{c}\text { Fusion of Q.L } \\
\text { with left lobe }\end{array}$ & $\begin{array}{c}\text { Transverse } \\
\text { fissure on Q.L }\end{array}$ & $\begin{array}{c}\text { Lingular } \\
\text { process }\end{array}$ & $\begin{array}{c}\text { Deep renal } \\
\text { impression }\end{array}$ \\
\hline Aktan et al., [5] & 54 & - & 4.0 & 15 & - & - & - \\
\hline Joshi et al., [16] & 90 & 6.0 & 2.2 & - & - & - & - \\
\hline Nagato et al., [17] & 61 & 6.56 & - & - & - & 21.31 & 9.84 \\
\hline Wahane \& Satpute [6] & 50 & 20 & - & - & - & 4.0 & - \\
\hline Khedekar \& Hattangdi [18] & 50 & 42 & 2.0 & 14 & - & - & - \\
\hline Patil et al.,[11] & 50 & 2.0 & - & - & 4.0 & - & 2.0 \\
\hline Present study & 20 & 10 & 5.0 & 20 & 5.0 & 15 & 10 \\
\hline
\end{tabular}

[Table/Fig-7]: Comparative findings of present study with previous studies.

${ }^{*}$ Q.L- Quadrate lobe

\begin{tabular}{|l|c|}
\hline Netter's classification & $\begin{array}{c}\text { Findings of present study } \\
\text { (No. of specimen/20) }\end{array}$ \\
\hline $\begin{array}{l}\text { Type I (Very small left lobe, } \\
\text { deep costal impressions) }\end{array}$ & N2 \\
\hline $\begin{array}{l}\text { Type II (Complete atrophy } \\
\text { of left lobe) }\end{array}$ & Nil \\
\hline $\begin{array}{l}\text { Type III (Transverse saddle } \\
\text { like liver, relatively large left lobe) }\end{array}$ & Nil \\
\hline $\begin{array}{l}\text { Type } 1 \text { V (Tongue like process } \\
\text { of right lobe) }\end{array}$ & Nil \\
\hline $\begin{array}{l}\text { Type V (Very deep renal impression } \\
\text { and corset constriction) }\end{array}$ & 02 \\
\hline Type VI (Diaphragmatic grooves) & 02 \\
\hline
\end{tabular}

[Table/Fig-8]: Findings of present study according to Netter's classification of fluid in additional fissures may be misinterpreted with liver cyst, intrahepatic haematoma or liver abscess. Implantation of peritoneally-disseminated cancer cells into these fissures gives similar appearance as intrahepatic focal lesions [14].

We encountered a single depression on anterior surface of one liver and multiple depressions on other liver among twenty specimens. These depressions have been described earlier as accessory hepatic fissures [15]. The shape of depressions in present study does not favour them as fissures. Therefore, we consider them as grooves which might be produced by diaphragmatic pressure.

\section{CONCLUSION}

This study concludes that liver is the organ presenting variations in a range of circumstances. We presented this 
study with majority of anomalous livers which may be linked with gastric volvulus, diaphragmatic hernia and portal hypertension. Atrophy, agenesis, presence of accessory lobes, additional fissures may mislead the diagnostic procedures as the enlarged processes like papillary process, lingular process may mimic the mass lesions, metastatic as well lymph node lesions while fissures, tunnel may confuse the diagnostician with abscess, haematoma and metastatic lesions. Therefore, the knowledge of these variations may be a fruitful finding for diagnosticians as well as surgeons. Present study was limited up to adult livers. We could not perform a comparative study with neonates or gender based study due to non availability of samples.

\section{REFERENCES}

[1] Standring.S. Gray's Anatomy: The Anatomical Basis of Clinical Practice $40^{\text {th }}$ ed. New York: Churchill Livingstone. 2008;116365.

[2] Sarala HS, Jyothilakshmi TK, Shubha R. Morphological variations of caudate lobe of the liver and their clinical implications. Int $J$ Anat Res. 2015;3(2):980-83.

[3] Nayak BS. A study on the anomalies of liver in the South Indian cadavers. Int. J. Morphol. 2013; 31(2): 658-61.

[4] Champetier J, Yver R, Letoublon C. A general review of anomalies of hepatic morphology and their clinical implications. Anat Clin. 1985; 7:285-99.

[5] Aktan Z A, Savas R, Pinar Y, Arsian O. Lobe and segment anomalies of the liver. Journal of anatomical society of India. 2001; 50(1): 15-16.

[6] Wahane A, Satpute C. Normal morphological variations of liver lobes: A study on adult human cadaveric liver in Vidarbha region. International journal of science and research. 2013; 814-16.
[7] Netter FH. Atlas of human anatomy. $2^{\text {nd }}$ ed. New York: Guilford press. 2000.

[8] Dev G, Sharma R, Sharma B. Hepatic papillary process - An anatomic variant of liver. JK Science. 2014; 16(4):184-85.

[9] Korn MA. Papillary process of the caudate lobe-erroneous sonography interpretation as space occupying lesion. Utraschall Med. 1991; 12(4):197-200.

[10] Auh YH, Rosen A, Rubenstein WA. CT of the papillary process of the caudate lobe of the liver. Am J Roentgenol. 1984; 142:53538.

[11] Patil S, Sethi M, Kakar S. Morphological study of human liver and its surgical importance. Int J Anat Res. 2014;2(2):310-14.

[12] Nayak BS, Kumar N, Rao SS, Reghunathan D, Patil J, Swamy Ravindra S. Tunnel for ligamentum teres: A rare variation of the liver. OA Case Reports. 2013 10;2(10):95.

[13] Cho KC, Baker SR. Air in the fissure for ligamentum teres: new sign of intraperitoneal air on plain radiographs. Radiology. 1991; 178(2):489-92.

[14] Auh YH, Lim JH, Kim KW. Loculated fluid collections in hepatic fissures and recesses: CT appearance and potential pitfalls. Radiographics. 1994; 14:529-40.

[15] Yoshimitsu, K, Honda H, Kuroiwa T, Irie H, Aibe H, Shinozaki K, Masuda K. Unusual hemodynamics and pseudo lesions of the noncirrhotic liver at CT. Radiographics. 2001; 21:S81-96.

[16] Joshi SD, Joshi SS, Athavale SA. Some interesting observations on the surface features of the liver and their clinical implications. Singapore Med J. 2009; 50(7): 715-19.

[17] Nagato AC, Silva MAS, Trajano ETL, Alves JN, Bandeira ACB, Ferreira TA. Valença SS, Bezerra FS. Quantitative and morphological analyses of different types of human liver. $J$ Morphol Sci. 2011; 28 (4): 275-79.

[18] Khedekar Deepak N and Hattangdi S S. Some interesting morphological features of liver lobes in mumbai population. Int $\mathrm{J}$ Med Res Health Sci. 2014; 3(3): 656-59.
AUTHOR(S):
1. Mr. Alok Saxena
2. Dr. Kishor Kumar Agarwal
3. Dr. Charul Jakhwal
4. Dr. Shivali Singh
5. Dr. Amal Rani Das

\section{PARTICULARS OF CONTRIBUTORS:}

1. Assistant Professor, Department of Anatomy, Veer Chandra Singh Garhwali Government Institute of Medical Science and Research, Srinagar, Uttarakhand, India.

2. Associate Professor, Department of Anatomy, Veer Chandra Singh Garhwali Government Institute of Medical Science and Research, Srinagar, Uttarakhand, India.

3. Junior Resident, Department of Anatomy, Veer Chandra Singh Garhwali Government Institute of Medical Science and Research, Srinagar, Uttarakhand, India.
4. Junior Resident, Department of Anatomy, Veer Chandra Singh Garhwali Government Institute of Medical Science and Research, Srinagar, Uttarakhand, India.

5. Professor, Department of Anatomy, Veer Chandra Singh Garhwali Government Institute of Medical Science and Research, Srinagar, Uttarakhand, India.

\section{NAME, ADDRESS, E-MAIL ID OF THE CORRESPONDING AUTHOR:}

Mr. Alok Saxena,

Assistant Professor, Department of Anatomy, Veer Chandra Singh Garhwali Government Institute of Medical Science and Research, Srinagar, Uttarakhand-246174, India.

E-mail: alok.sxna@gmail.com

FINANCIAL OR OTHER COMPETING INTERESTS: None. 